\title{
Does philosophy kill culture?
}

\author{
Jason Chen \\ Susan T Gardner \\ Capilano University, North Vancouver, Canada \\ Correspondence: sgardner@capilanou.ca
}

\begin{abstract}
Given that one of the major goals of the practice of Philosophy for Children (P4C) is the development of critical thinking skills (Sharp 1987/2018, pp. 4 6), an urgent question that emerged for one of the authors, who is of Chinese Heritage and a novice practitioner at a P4C summer camp (thinkingplayground.org), was whether this emphasis on critical thinking might make this practice incompatible with the fabric of Chinese culture. Filial piety (孝), which requires respect for one's parents, elders, and ancestors is considered an important virtue in Asian culture, as is the preservation of harmony. But if one of the goals of $\mathrm{P} 4 \mathrm{C}$ is to teach youngsters to courageously pursue reasoned dialogue, does this not set-up young Asians for serious conflict when they come face-to-face with positions that are articulated by elders, but which are ones to which they are diametrically opposed; a racist grandmother, for instance, or an uncle who insists that those at the Tiananmen Square uprising were nothing but hooligan's. It is this question that we will explore in this presentation. In the process, we will come to the conclusion that, when positions seem irreconcilable, rather than continuing to pursue rigorous critical interchange that may do little other than escalate insult, the facilitator, rather, ought to move toward creating a deeper understanding of each position juxtaposed against its opposing view (a process that we refer to as 'collaborative caring'), so as to produce side-by-side understanding, knowing that communal bonds have been maintained and, hence, that the opportunity for genuine reasoned collaborative inquiry on other issues and at future times remains open.
\end{abstract}




\section{Key words}

collaborative caring, critical thinking versus filial piety, education in China, $\mathrm{P} 4 \mathrm{C}$ in the Asian context, philosophy and culture

\section{Introduction: Does philosophy kill culture?}

Although not the central goal, one of the sub-goals of the practice of Philosophy for Children (P4C), a world-wide educational practice founded by an American philosopher Matthew Lipman in the 1970s (Lipman et al. 1980, Lipman 1988), is the development of critical thinking skills (Sharp 1987/2018, pp. 40-46). A central question that emerged for one of the authors, a Chinese-Canadian, and a novice practitioner at a P4C summer camp (thinkingplayground.org), was whether this emphasis on critical thinking might make this practice incompatible with the fabric of Chinese culture.

Although I am a naturalised Canadian and hence a child of Canadian culture, my parents came to Canada in 1989 and my heritage is inevitably still tied to China. Thus, there are times when I question what part of my Chinese culture I ought to embrace, as well as include, in the practice of $\mathrm{P} 4 \mathrm{C}$. Part of this problem, it seems to me, is that critical thinking is, in a sense, assumed to be value-free, and therefore assumed to be a positive experience for all students. However, this logocentric view of the West may seriously challenge certain cultural customs and traditions, particularly those surrounding relationships and hierarchy in China.

This became evident to me in the summer of 2017, as part of our P4C camp, when we raised a scenario to the campers on what they ought to do in the case of having a racist grandmother: should they go along with that grandparent and simply say nothing, or stand up and correct her? An overwhelming majority of Canadian children thought that standing up for what's right is important. However, our international students from South Korea believed that respect for an elder was more important than standing up for some abstract ideal. My co-facilitator and I found it difficult to negotiate a genuine dialogue between these two vastly different points of view.

This difference in cultural perspectives became further evident in a discussion at the $24^{\text {th }}$ World Congress of Philosophy in Beijing, China. When the example of our day camp 
activity was brought up, many scholars from China and South Korea also agreed that they would not simply stand up and correct a racist elder due to respect. Indeed, they went even further by suggesting that, in a Community of Inquiry, they would never bluntly say 'I disagree' (a response that a South Korean P4C elder apparently often heard between Lipman and Sharp at their various meetings at The Institute for the Advancement of Philosophy for Children), as they viewed this as bordering on rudeness. They suggested, rather, that what should be said would be more along the lines of: 'That's interesting. I have a different way of seeing the situation'.

One might argue that the former response is more authentic, and more efficient at moving the dialogue toward a deeper understanding of the issue. Supporting this view, Gardner, in her critical thinking text (2009) has argued that moving toward truth requires that we learn to get comfortable throwing out what is false. As well, she points out that being open to opposing viewpoints is essential to developing a flexible mind. Burton, in his book On Certainty (2008) makes the same claim.

On the other hand, one might argue that the latter response that focuses on preserving relationships, even if this stalls the movement toward a deeper understanding of the issue, and even if it requires a silencing of one's deeply held beliefs (as in the case of being passive in the presence of a racist grandmother), also has merit.

The question that we would like to focus on in this paper is whether or not we can bridge the gap between these two positions. My question is, when I move to China, which is my goal, and when I engage in educational practice, which is also my goal, how should the practice of $\mathrm{P} 4 \mathrm{C}$ be altered (if at all) in this Asian context? In the process, this quest might shed light on the relationship between critical and caring thinking, both being advocated in P4C circles (Sharp 2004/2018).

\section{Relationships within the Chinese context}

The question that I will be analysing is whether focusing on efficient effective authentic dialogical ways of thinking through issues, that seems central to the Western way of practicing $\mathrm{P} 4 \mathrm{C}$, might kill what is central to Asian culture. In order to answer this question, I must first try to distil what I take to be central to Chinese culture as it affects my life, particularly in light of the dramatic changes that China has experienced since the 
communist revolution. My viewpoint here is borrowed from my parents who lived through the cultural revolution but who, nonetheless, believe that the basic threads of Chinese culture are those that come from Confucianism. The following are excerpts from the Analects: 1:2 (Eno 2015):

It is rare to find a person who is filial to his parents and respectful of his elders, yet who likes to oppose his ruling superior. And never has there been one who does not like opposing his ruler who has raised a rebellion.

The [ruler] works on the root-once the root is planted, [governance] is born. Filiality and respect for elders, are these not the roots of [humanity]?

Filial piety, then, requires that one respect one's parents, and this value is considered to be the most fundamental of Confucian values, and the root of all others. Confucius was very much concerned with natural order and governance. To him, filial piety is a prime virtue and the starting point. Humaneness is the ultimate goal, but it must start with filial piety. This fundamental human bond is between the parent and child. Children are expected to obey their parents, and to listen to their wisdom. This filial piety is based on that reciprocity; the child is expected to support his or her parents in old age as she was once nurtured. This obligation to respect one's parents also extends to one's ancestors in worship.

Thus, in his online article Filial Piety in the Chinese Culture, Aris Teon quotes Akiko Hashimoto as saying:

Filial piety in East Asia today is at once a family practice, an ideology, and a system of regulating power relations. As practiced in the family, filial piety defines a hierarchical relationship between generations, particularly that of the parent and the child. In this ordered space, filial piety prescribes the ideology of devotion by the grateful child to the parent, and also places debt and obligation at the heart of the discourse on parent-child relationships. Contemporary filial piety is in this sense not merely a vestige of a past family custom, but an ongoing practice of surveillance and control that unleashes considerable disciplinary power. Using a discourse of gratitude and indebtedness, a hierarchy of power is reproduced in everyday life, privileging the old over the young and the parent over the child.

And Shaohua Hu says 
What makes Confucianism distinctive is that it regards filial piety as the uttermost virtue in society, thereby sacrificing individualism and patriotism at the altar of family. Two cases illustrate Confucian emphasis on family value. In one case, Confucius thought that if a father had stolen a sheep, his child should conceal the misconduct instead of bearing witness against him (Confucius, 13:8). Mencius said that if Emperor Shun's father committed a murder, the emperor might abandon his empire and run away with his father (Mencius, 7a: 35). Confucian emphasis on filial piety has had a great impact on Chinese society in general and China's political culture in particular (pp. 353-354)

\section{The clash with reason}

From an abstract point of view, this Confucian focus on creating and preserving harmony and relationships may seem both attractive and non-contentious. In practice, however, challenges quickly arise, particularly for a Chinese-Canadian like myself, when interacting with my parents who were born in China. For example, to my father who said that homosexuality is wrong, my response was: 'No Dad, this is the way you have to see it ...', and then, oops, it is clear that my father is offended. To my mother who said that she would never forgive me if I married a black person, my response was: 'Mom, that is kind of racist, isn't it?' and then, oops, it is clear that my mother is offended.

And in China itself, the situation can be even trickier. My Chinese uncle said, for example, that the students in Tiananmen Square deserved to be shot because they were just a bunch of trouble-making hooligans. Though my viewpoint differed significantly from his version of events, I was left speechless by both the threads of Confucianism and the potential presence of authoritarian brainwashing.

And speaking of authoritarian brainwashing, this might be precisely how children of the Enlightenment might characterise culture in general. After all, most of the cultures of preenlightenment Europe insisted that religious and political institutions were such that questioning their validity was out of bounds. Might not culture indeed be like the opiate of the people, as Marx suggested of religion? And wasn't it precisely the sword of reason that served as the emancipatory weapon that had hitherto subjugated most of humanity? Should a teacher in feudal England have been worried that his or her educational 
practices might destabilise the rigid relational hierarchy that was considered natural at the time? Should I worry, when I return to China, if engaging youngsters in philosophical dialogue might show disrespect when that dialogue threatens the legitimacy of the background culture?

We will attempt to answer these questions by investigating a more nuanced form of reasoning as found in the practice of Philosophy for Children which also emphasises both collaborative and caring thinking. It is to these topics that we will now turn.

\section{A more nuanced form of reasoning}

There is much to celebrate about human rationality, including importantly the fact that reason has been able to cut away many of the crippling oppressive ties of superstition, religion and tradition. It is through reason that the beacon of individual freedom was lit.

On the other hand, reason unmoored from all particular human values might also be accused of leading to great human misery. Pure instrumental reason, after all, leads to the sorts of discoveries that expand the human capacity for inhumanity, such as the killing machines used in the world wars in the $20^{\text {th }}$ century and, in our time, the potential inhumanity embedded in the over-use of technology to the detriment, not only of human relations, but for the very survival of life as we know it on this planet.

To their credit, the founders of P4C Lipman and Sharp offered up a more nuanced view of rationality (or critical thinking) by adding to it, two vital elements: collaboration and caring.

\section{(a) Collaboration}

The foundational pedagogical anchor of P4C is the community of philosophical inquiry (CPI). Lipman (1991, p. 15) credits Charles Sanders Peirce (1955) with coining the phrase as a descriptive of the kind of inquiry that takes place in scientific communities, in which inquirers intently analyse others' positions, ferret out assumptions, draw inferences and build on one another's ideas. In embracing this form of collaborative thinking, Lipman moves away from the more traditional celebration of rationality as depicted by Rodin, in his famous sculpture The Thinker: a wise man figuring out the world's problems all by 
himself (sic). This notion of collaboration also finds reflection in Jurgen Habermas' description of communicative as opposed to strategic action. According to Habermas in Postmetaphysical thinking (1992, henceforth PMT), the former strives toward reaching understanding, while the latter strives toward exerting influence (PMT, p. 79). As Gardner notes in her article, The Evolution of Connectivity: A Bridge Beyond (2011), Habermas emphasises that success in communicative action is always a function of both the speaker and the hearer (PMT, p. 80). Specifically, Habermas says of communicative action that

The independent performances that are here demanded from the subjects consist of something different than rational choices steered by one's own preferences; what these subjects must perform is the kind of moral and existential self-reflection that is not possible without the one taking up the perspective of the other. Only thus can there emerge a new kind of social integration among individuals who are individualized and not merely manipulated. The participants must themselves generate their socially integrated forms of life by recognizing each other as autonomous subjects capable of action and, beyond this, as individuated beings for which they have taken responsibility. (PMT, p. 199)

As Gardner points out (2011), the distinguishing feature of this Habermasian model is that Habermas stresses that rationality lives - in fact can only be actualised -in what Buber (1958) would call the 'in-between.' According to Habermas in The theory of communicative action (1992, henceforth TCA), I must recognise that whenever I speak, I raise what he refers to as a 'criticizable validity claim for the proposition $p$, a claim that the hearer can accept or reject with good reason' (TCA, p. 11). Thus, in order to claim the dignity and autonomy that Kant argued adhered to rationality, I must, according to Habermas, reflect on whether what I have said is vulnerable to the sort of falsification that my hearer suggests. I cannot, in other words, assert that my claim is true merely by referring to some a priori metaphysic (hence the penetrating title of Habermas' book Postmetaphysical Thinking); I must, rather, remain constantly open to the challenge that my claim may turn out to be inadequate from the other's point of view. Specifically, he says:

Anyone participating in argumentation shows his [sic] rationality or lack of it by the manner in which he handles and responds to the offering of reasons for or against claims. If he is 'open to argument,' he will either acknowledge the force of those reasons or seek to reply to them, either way he will deal with them in a 
'rational' manner. If he is 'deaf to argument,' by contrast, he may either ignore contrary reasons or reply to them with dogmatic assertions, and either way he fails to deal with the issues rationally. (TCA, p. 18)

Habermas quotes Robert Horton who, in studying Evans-Pritchard's observations of the justificatory practices of the Azande, observed that

Here then we have two basic predicaments: the 'closed' - characterized by lack of awareness of alternatives, sacredness of beliefs, and anxiety about threats to them; and the 'open'-characterized by awareness of alternatives, diminished sacredness of beliefs and diminished anxiety about threats to them. (TCA, p. 61)

Thus, according to Habermas, if I am prepared to open any and all of my beliefs, judgements and opinions (as opposed to, importantly, my character as a person) to the critical gaze of the other, and if the other likewise comes out to meet me with the same openness, neither of us can predict in advance what might emerge in the ensuing dialogue, though both of us can connect under the auspices of reasonable presence.

The problem that this inspirational picture ignores is that the other, if steeped in tradition, may be unwilling and/or unable to come out to meet me. What is one supposed to do when faced with a potentially 'closed' mind?

One potential solution is that, while I cannot open the mind of another, I can open up my own and, in so doing, at least model 'openness' by articulating my own position, with an invitation to consider the adequacy of the anchoring reasons.

Battersby and Bailin, in their article Reason Appreciation (2007), echo this point by making the claim that reasoned articulation that is open for restructuring breeds respect when they say that 'reasoning is the least manipulative and most respectful way to motivate change in belief and behaviour. To give reasons rather than threats, to reason with, rather than cajole or manipulate, is ... to respect the autonomy of the other person' (p. 113.)

This suggestion, that I invite another into my own position, even if that means opening up a one-way street, differs substantially from the kind interchange of interlocutors each offering the other criticisable validity claims that each assume is open to refutation. A one-way street encounter can be described as one is which critical thinking is not so much focused on opposing positions, but rather almost entirely on one's own. While this seems 
less satisfactory than communal inquiry, it keeps the potential for communication and communal connection open.

So, thinking back on my encounters with my parents, it is clear to me that I did not enter those dialogues with the potential of a one-way street in mind. I entered the arena, rather, with my sword drawn. I wasn't in the least interested in carefully articulating my own beliefs so much as destroying theirs. It is also clear to me that my silence when confronted by my uncle was equally unwarranted. The first approach was too strong, the second not strong enough. In both instances, I could have articulated my position in such a way that showed I was humbly open to being shown a different way of seeing the situation. In both instances, I could have ensured that respect and caring were evident in the interchange. So it is to this notion of caring that we will now turn.

\section{(b) Caring}

Caring thinking in P4C is described in multiple and often contradictory ways. Lipman (1995) seems to suggest that our caring ought to be for the reasoning process itself, as well as for that on which it focuses. Sharp (2004) differs slightly from Lipman by including care for the other. We will suggest that there is a third kind of caring that needs to be taken into account, at least in those instances when a CPI focuses on value questions. This third kind of caring, that is informed by Object Relations Theory, suggests that we attempt to see others in a richer way than merely as participants in dialogue. It suggests, rather, that we see others as uniquely mired in their own individual interpersonal histories and that, as a result, the degree of freedom to 'follow reasons where they lead' (the ideal of a CPI) that is open to them may be limited. To see persons in this way will have potential ramifications for facilitating a CPI.

So let us briefly review Lipman and Sharp's positions, and then move toward a more detailed elucidation of this third kind of caring: seeing others within the context of their internal communities.

\section{i. $\quad$ Caring for the process}

In Lipman's hands (1995), caring thinking seems to translate into caring for the thinking process itself, as well as caring deeply for that to which the thinking process is applied. We should care deeply that we make progress in this enterprise of thinking together. Lipman says: 
Thus, caring is a kind of thinking when it performs such cognitive operations as scanning for alternatives, discovering or inventing relationships, instituting connections among connections and gauging differences. (1995, p. 8)

Without caring, higher-order thinking is devoid of a values component. If higher-order thinking does not contain valuing or valuation, it is liable to approach its subject matters apathetically, indifferently, and uncaringly, and this means it would be diffident even about inquiry itself (p. 12).

\section{ii. Caring for the other}

In Sharp's hands, caring thinking seems also to slide into caring for the other - it is in this sense that $\mathrm{P} 4 \mathrm{C}$ is sometimes credited with enhancing empathy. To Sharp, caring is the 'sense of relationship to the world and to others' (2004/2018, p. 18). Though, Sharp argues, in a way similar to Lipman, that caring requires us to make judgements and to act, she also believes that authentic dialogue requires caring thinking to be intentional so that it may nurture growth in the other. She says, for instance, of the community of inquiry, that it is 'an experience of caring. It is based on a trust that whatever happens in the eternal world, communication, love, compassion, solidarity, creativity and sharing ideals are what really matters' (p. 214); that if I care, 'I have the capacity to wish the other well, to take care of, to attend to, to nurture, and to help some thing or someone grow' (p. 213). If we are to foster caring thinking, much more is needed than logic and reason (p. 213); in a community of inquiry, not only do participants learn to care for how well they are able to reason together, 'they also learn to care for each other as they proceed in the inquiry itself' (p. 213).

For Sharp then, capacity to care focuses not only on the tools of inquiry but also how we care for each other in the process of dialogue. The good life is intrinsically tied to what we care about.

iii. Caring for one's internal community.

There is a third kind of caring that, we suggest, needs to be taken into account in a CPI, at least a CPI that focuses on value issues. This may have been overlooked in P4C circles because of the assumption that engaging in a community of inquiry is the same regardless of context; that the transplant of engaging in a scientific community of inquiry, a la Pierce, to a philosophical community of inquiry, a la Lipman, is relatively unproblematic. This 
assumption ignores the fact that we all of us have an internal audience whose voices usually only register within the context of value analysis. If this is true, then a philosophical community of inquiry has the potential to be qualitatively different from a scientific community of inquiry. Those within your internal audience, for instance, probably don't care if you agree or disagree with the claim that Avian Influenza should be studied in this way rather than that. They may, however, care enormously if you agree or disagree with whether sexual orientation should be taken into account when discussing adoption.

This claim that we all carry around an internal audience is the baseline assumption of Object Relations Theory (Harry Guntrip 1974). The primary focus of Object Relations Theory is the study of how dysfunctional early childhood interpersonal relations can result in subsequent serious mental illness. Our concern here, by contrast, is just to note that all of us inevitably check in, whether consciously or not, with those from whom we have introjected values (Mead, 1934) when those values are at stake. Thus, when we engage in a community of inquiry that focuses on value, it might be helpful to take into account that each of us is surrounded by internal significant others who have a stake in the discussion.

The primary payoff of seeing others within the context of their internal communities will, hopefully, be enhanced sympathy. That is, remembering that we each bring an internal audience to any communicative encounter that focuses on value may help to assuage anger over the fact that the other will not listen to reason! If we keep in mind that the other may suffer unbearable shame in the presence of his or her internal audience for moving away from a particular stance, then understanding may be the order of the day.

What this suggests is that, when communities potentially clash, it might be helpful to articulate a different notion of what it means to be open to a different way of seeing the issue. Instead of insisting that one be genuinely open to counterexample with regard to one's criticisable validity claims, one might suggest being open to just seeing the different viewpoint of the other and, in seeing that difference, develop a more penetrating understanding of both forms of life.

In their article Reasoning (Or Not) With The Unreasonable (2019), Gardner et al. likewise suggest that, in the presence of what appears to be irreconcilable difference, an internal 
analysis of the other's position (as opposed to demanding external justification) might prove enlightening. More specifically, they say:

This suggests, then, that when faced with a mind closed to alternative views, a productive line of approach would be to thoroughly question the other so that one comes away from the communicative exchange with a deeper understanding of the other's position, rather than worrying about whether or not one's own position is being heard. In the process, one might find areas of overlap that can serve as opening for actual dialogue. As well, one might take this opportunity to probe potential contradictions as they come to light. (p. 5)

This questioning of the other assumes that the other is willing and/or able to offer reasons in support of his or her position. If this is not the case-if the other is unwilling or unable to offer such reasons - a more penetrating understanding might still be possible by probing into the causes (as opposed to reasons) of their deeply held belief; what Gardner et al. refer to as a 'genetic investigation.'

In such an investigation, our attempt would be to create question-rungs that allow us to ladder down into view of the core values of the other. (p. 6)

Another way of putting this point would be to say that partaking in a genetic investigation is an attempt to figure out how your position on a particular issue fits within the narrative of your life as you see it (MacIntyre). Or yet another way would be to say that I am trying to see you as a person, rather than just a talking head. (p. 6)

Within the halo of this form of care, which translates into a sensitivity to the presence of internal audiences which we all carry around in our heads - and which, for some, may be extremely demanding, we arrive at the conclusion that engaging in the sort of ideal speech act of which Habermas speaks may not always be possible. Nonetheless, a penetrating interchange may not only be possible, but fruitful in the sense of enhancing understanding and maintaining bonds, and hence keeping open the possibility of a more rigorous reasoned interchange on other topics and in future times. 


\section{Moving from 'rigorous reasoning' to 'collaborative caring'}

In the face of irreconcilable difference, the onus lies with all of us to hold onto respect for the other by recognising that the other's internal audience may make it impossible to genuinely consider an alternative to the position to which they are wedded. The suggestion here is that, in such situations, rather than gearing up for battle or leaving the field altogether, one first articulate one's own position with precision and care, while being open to critique; that one then assist the other in ferreting out the reasons for why they hold so strongly to the contrary position; and finally, if reasons are not forthcoming, exploring with the other why they are so passionately wedded to the position they hold.

The result of such an encounter will not be the sort of socially integrated form of life of which Habermas speaks. However, nor will it be two ships passing in the night. The vision will be of companions, perhaps walking side-by-side on this particular issue, but who have found a way to respectfully and caringly understand one another, despite lack of agreement. A way has been found, in other words, to dislike one another's points of view on a particular issue, but not dislike each other as a result. A way has been found, in still other words, to 'collaborate on caring,' even if reasoned collaboration with regard to truth is not possible. In so doing, such collaborative caring leaves the door open to the possibility that, on other issues and at future times, collaborative reasoned inquiry may indeed be possible.

This suggestion that there may be legitimate times to back away from bashing away at one another is similar to the point made by Levitsky and Ziblatt in their book How Democracies Die (2018). They argue that it is imperative that those of differing political bent stop trashing each other over narrow disagreements. This is so because coalitions between like-minded groups are not enough to defend democracy. Democracies require, rather, coalitions that bring together groups with dissimilar-even opposing-views on many issues. We need to remember, in other words, that while we may disagree with a neighbour about abortion, perhaps we will agree on health care; that while we may dislike our neighbour's view on immigration, we may still be able to work together on raising the minimum wage; that though we may loathe the fact that a business executive fights for tax cuts for the rich, we may nonetheless find fruitful integrated ways to champion the public school system. And remembering that we each must answer to our own internal communities, and not just to external others may help mitigate the anger that tends to surface when the other can't seem to hear the obvious merits of our position. 
None of this is to say, of course, that we ought to strive to live comfortably with any position that another adopts, no matter how abhorrent. If a viewpoint leads to direct harm to others, one's self-identity may require that the relationship be terminated, or indeed one may feel duty-bound to try to prevent any anticipated harm. The suggestion here is, rather, that when differences are vast but not at the breaking point, the sort of give and take, reason and counterexample banter that is common in philosophical inquiry might be better kept in abeyance. In such situations, a move toward acquiring a deeper understanding, both of self and other, may be a far more productive encounter.

\section{Conclusion: does philosophy kill culture?}

To answer the original question, 'does philosophy kill culture?', the first answer seems to be that if reasoned dialogue is respectful and moderate, it may actually invigorate culture. As Habermas points out, in order to participate in genuine dialogue 'participants must themselves generate their socially integrated forms of life' (PMT, p. 199). This suggests that participants in culture must constantly renew their cultural life through dialogical participation with others; they must regenerate their socially integrated forms of life. ${ }^{1}$

On the other hand, if positions seem incommensurable, and if we mean by philosophy the kind of direct critical dialogue of the Habermasian sort, then the answer seems to be 'no': philosophy will not kill culture because, in such situations, it will probably be ineffective. People will just close their minds to viewpoints that they perceive as insulting to the audiences within.

This suggests, then, that those of us who seek to connect even when differences are vast, should at least consider moving away from the typical philosophical path of critical interchange and move toward attempting to acquire a deeper understanding of the other by trying to draw out the reasoned scaffolding of their positions, while being radically open to the other visiting our own.

\footnotetext{
${ }^{1}$ It should be noted, at this juncture that, filial piety aside, this form of dialogue is not necessarily antithetical to Confucianism. As Chi-Ming Lam notes in his article Confucian rationalism (2014), Confucius believed that teaching benefits teachers and students alike, and that hence Confucius not only welcomes criticism from his disciples as a tool for self-improvement, but also expects them to consider, question, and criticise his teachings (p. 1455).
} 
As Gardner et al. (2019) point out, such efforts show that I am attempting to figure out how your position on a particular issue fits within the narrative of your life ... that I am trying to see you as a person, rather than just a talking head.

And they go on to say that

... in coming to understand the narrative of the other, I may see that it has merit, even if it is not a way of life that I would choose for myself. If that is the case, I may be able to double down on trying to find ways in which our differences can be accommodated that do not, in the process, trample either of our disparate core values. (p. 7)

And so, returning to the situations in which my father said that he believed homosexuality to be wrong, and my mother who seemed to possess racist tendencies, and my uncle who has embraced the politically correct interpretation of Tiananmen square, it seems to me that the best approach would have been to articulate my reasoned view in a non-judgmental way, so as to be true to my own internal audience. And, thereafter, if there was any hint of willingness, I would follow Gardner et al.'s (2019) suggestion and try to find out not only the scaffolding of their viewpoints but, as well, why it is so important to them. In all these instances, I believe our mutual bonds would have been strengthened both by my deeper understanding and the attenuation of my annoyance with positions that seemed irrationally unreasonable.

And, retuning, to the P4C camp in which we raised a scenario to the campers on what they ought to do in the case of having a racist grandmother (should they go along with that grandparent and simply say nothing, or stand up and correct her), this new insight suggests that we counsellors could have done a lot more than simply try to intermesh the stated but opposing views of the Canadian and South Korean youngsters. We might have tried to deepen understanding on both sides without attempting to estimate which side was superior. As Gardner et al. (2019) put it:

when a reasoning impasse is encountered ... then clearly utilizing such questions as 'how do you think you came to hold that view,' or 'do you know why you hold that view so strongly,' or 'have you always held that view,' or 'is it possible that you hold that view because ...', would be vital probes for enhancing depth all 
around, rather than being perceived as illegitimate personal insertions in what is supposed to be a purely reasoned dialogue. (p. 7)

And so, finally, with regard to practicing P4C in China, it does seem to me that the typical plain vanilla interchange of participants in a Philosophical Community of Inquiry, in which positions are stated boldly yet are open to critical scrutiny may, in some instances, work (see footnote 1). However, in other instances, there may be little progress, either because views are incommensurate or because everyone espouses the same position. In such situations, it seems to me that the facilitator ought to move toward creating a deeper understanding of each position juxtaposed against its opposing view, even if the facilitator has to articulate that opposition, e.g. 'my friends in Canada would probably have a different position'. This new insight suggests that the facilitator need not feel pressure to prod participants to try to figure out, through communal inquiry, which position is more adequate. The facilitator, rather, should, when this is deemed appropriate, nurture 'collaborative caring' so as to produce side-by-side understanding with regard to the issue at hand, knowing that communal bonds have been maintained and, hence, that the opportunity for genuine reasoned collaborative inquiry on other issues and future times remains open.

\section{References}

Battersby, M \& Bailin, S (2007) Reason appreciation. In HV Hansen \& R Pinto (eds) Reason reclaimed. Newport, VA, Vale Press, pp. 107-120.

Buber, M (1958) I and thou. $2^{\text {nd }}$ ed. New York, NY, Charles Scribner's Sons.

Burton, RA (2008) On being certain: On believing that you are right even when you are not. New York, NY, St. Martin's Griffin.

Eno, R (2015) The analects of Confucius: An online teaching translation. Indiana University Bloomington, IN. Available from http://www.indiana.edu/ p374/Analects of Confucius (Eno-2015).pdf

Guntrip, H (1974) Schizoid phenomena, object relations and the self. New York, NY, International Universities Press. 
Gardner, ST (2009) Thinking your way to freedom: A guide to owning your practical reasoning. Philadelphia, PA, Temple University Press.

Gardner, ST (2011) The evolution of connectivity: A bridge beyond. In B Weber, E Marsal \& $\mathrm{T}$ Dobashi (eds) The politics of empathy: New interdisciplinary perspectives on an ancient phenomenon. Piscataway, NJ, Transaction Publishers, pp. 51-59.

Gardner ST, Anderson, A \& Henry, W (2019) Reasoning (or not) with the unreasonable. Analytic Teaching and Philosophical Praxis, Spring, pp. 1-10.

Habermas, J (1992) The theory of communicative action. (TCA) Vol. 1: Reason and the Rationalization of Society. Trans. Thomas McCarthy. Boston, MA, Beacon Press. (German text 1981).

Habermas, J (1992) Postmetaphysical thinking: Philosophical essays (PMT). Trans. William Mark Hohengarten. Cambridge, MA, MIT Press.

$\mathrm{Hu}$, Shaohua (1997) Confucianism and western democracy. Journal of Contemporary China, 6(15), pp. 347-363.

Lam, Chi-Ming (2014) Confucian rationalism. Educational Philosophy and Theory, 46(13), pp. $1450-1461$.

Levitsky, S \& Ziblatt, D (2018) How democracies die. New York, NY, Crown.

Lipman, M (1988) Philosophy goes to school. Philadelphia, PA, Temple.

Lipman, M (1991) Thinking in education. Cambridge, UK, Cambridge University Press.

Lipman, M (1995) Caring as thinking. Inquiry: Critical Thinking Across the Disciplines, 15(1), pp. 1-13.

Lipman, M, Sharp, AM \& Oscanyan, FS (1980) Philosophy in the classroom. Philadelphia, PA, Temple.

Mead, GH (1934) On social psychology. A Strauss (ed). Chicago, IL, University of Chicago Press. 
Pierce, CS (1955) The fixation of belief. In J Buchler (ed) Philosophical writing of Pierce. New York, NY, Dover, pp. 5-22.

Sharp, AM (1987/2018) What is the Community of Inquiry? In MR Gregory \& MJ Laverty (eds) Community of Inquiry with Ann Margaret Sharp: Childhood, philosophy, and education. New York, NY, Routledge, pp. 38-48.

Sharp, AM (2004/2018) The other dimension of caring thinking. In MR Gregory \& MJ Laverty (eds) Community of Inquiry with Ann Margaret Sharp: Childhood, philosophy, and education. New York, NY, Routledge, pp. 209-214.

Teon, A (2016) Filial piety in the Chinese culture. The Greater Chinese Journal. Available from https://china-journal.org/2016/03/14/filial-piety-in-chinese-culture/ 